\title{
Entry, Exit and Mergers: A Competitive Equilibrium Model with Financial Frictions.*
}

\author{
Román Fossati ${ }^{\dagger}$ \\ Department of Economics, UNLP
}

November 15, 2005

\begin{abstract}
This paper examines a dynamic stochastic model of a competitive industry with heterogeneous firms that allows for entry, exit and mergers of firms in equilibrium. The model we build is an extension of a modified version of Jovanovic and Rousseau's (2002) model that introduces financial frictions, describes the market for corporate control and endogenizes its equilibrium price, and develops a stationary equilibrium à la Hopenhayn (1992). It provides a theoretical framework within which to study factors affecting variables such as entry, exit and investment through direct unbundled capital good purchase and mergers. This work contributes to the literature by suggesting another explanation to many empirical regularities and describing one more mechanism through which aggregate liquidity shocks may affect merger activity. The results suggest that due to asymmetric information about entrepreneur's survival probabilities aggregate liquidity shocks may contribute to codetermine the turnover rate of firms and investment levels through mergers.
\end{abstract}

JEL Classification System: G34,O3,D92

Keywords: Entry and Exit, Financial Frictions, Mergers, Technological Change.

${ }^{*}$ This paper was prepared as Thesis for the Master's in Economics at UNLP. I would like to thank my thesis' director, Enrique Kawamura, for his valuable advice. I also appreciate comments by Irene Brambilla, Hugo Hopenhayn, Juan M. Sánchez and seminar participants at UNLP. All remaining errors are exclusively my responsibility.

${ }^{\dagger}$ National University of La Plata and Provincial Bureau of Statistics (Ministry of Economy of the Province of Buenos Aires). E-mail: fossatiroman@yahoo.com.ar 


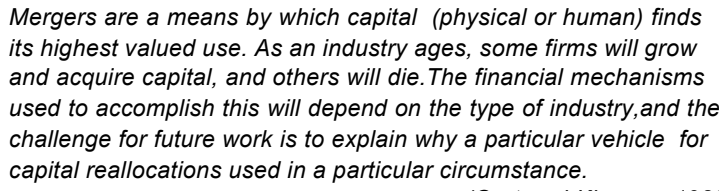

(Gort and Klepper, 1982)

\section{Introduction}

Entrepreneurs typically have no means to fund their projects, and they must finance greater amounts than incumbents. ${ }^{1}$ According to empirical evidence, entrepreneurs bear substantial risk. New entrants are smaller (the size of new firms is between $40 \%$ and $60 \%$ of the size of incumbents), exhibit lower survival rates (between $20 \%$ and $40 \%$ of new firms fail during the first two years and only 40\%-50\% of entering firms survive more than seven years), and have also greater variance in their growth rate. ${ }^{2}$ The high rate of infant mortality represents great uncertainty about entrepreneur's quality. Young firms come to financial markets as unknown entities. Then, expensive loans are granted to new firms because of asymmetric information about firms' survival probabilities. ${ }^{3}$ As entrepreneurs take on more debt and the cost of capital is higher for entrants than for incumbents, initial capital requirements may constitute a big component in the cost of entry to an industry.

On the other hand, models of industry dynamics suggest a negative relation between sunk entry costs and firms' turnover rate. ${ }^{4}$ In particular, we rely on the Hopenhayn's (1992) paper that develops a model which endogenously determines entry and exit of firms. It considers that as a consequence of idiosyncratic uncertainty substantial amounts of resources are reallocated across firms, from contracting and exiting ones to new and expanding ones.

In reality, exit can take place through either failure or acquisition, while firm's productive capacity expansion can take place through either direct purchase of new capital goods or mergers. Empirical evidence on aggregate merger and acquisition (M\&A) activity, and entry and exit of firms in the U.S. economy reported a positive correlation between horizontal mergers and the turnover rate of firms. More specifically, according to empirical

\footnotetext{
${ }^{1}$ Cooley and Quadrini (1998) present empirical evidence that small and younger firms take on more debt.

${ }^{2}$ These stylized facts has emerged from a number of empirical studies. See Caves (1998), Sutton (1997), and Dunne, Roberts and Samuelson (1989a,b).

${ }^{3}$ Wynne (2005).

${ }^{4}$ We review the relevant literature on dynamic industry equilibrium in the next section.
} 
regularities documented in the literature, entry leads mergers. In addition, it have been documented an increase in merger activity and a change in firms' investment composition over time: during the past two decades mergers and acquisitions have grown relative to direct investment in (unbundled) capital goods. ${ }^{5}$

Based on these facts, we suggests that mergers and processes of entry and exit are codetermined. Then, determinants of the turnover rate of business may also affect mergers. The interaction between these variables has attracted the attention of researchers, and some explanations have been provided to shed light on this issue. In addition, a relevant aspect illustrated by Caves (1998) is that productivity growth for an industry as a whole depends to an important degree on the redistribution of shares toward more productive units and not just on growth of the units' individual productivity. As mergers play the same economic role as entry and exit (asset reallocation) ${ }^{6}$ it seems natural then to study these processes within a unified framework.

We develop a theoretical framework within which to study factors affecting variables such as entry, exit and investment through direct unbundled capital good purchase and mergers. The model we build is an extension of a modified version of Jovanovic and Rousseau (2002) model that introduces financial frictions, describes the market for corporate control and endogenizes its equilibrium price, and develops a stationary equilibrium à la Hopenhayn (1992). The model replicates many empirical regularities documented in the literature and offer an alternative explanation to the increase in merger activity and to the change in the composition of investment evidenced in the past two decades.

The paper is organized as follows. Section 2 reviews the literature. Section 3 describes the model. Section 4 characterizes the stationary equilibrium and exposes the description of the market for corporate control. In Section 5 the comparative static exercises we are looking for are presented. Section 6 provides the final remarks.

\section{Literature.}

In this section first we review the relevant literature on dynamic industry equilibrium $^{7}$, and we then review the work on mergers.

\footnotetext{
${ }^{5}$ Jovanovic and Rousseau (2001, 2002a).

${ }^{6}$ Manne (1965).

${ }^{7}$ For a more detailed discussion on firm and industry dynamics see Caves (1998), Sutton (1997), Dune Roberts and Samuelson (1989a,b) and Lambson and Jensen (1995).
} 
The emerging theoretical literature on industry dynamics has contributed to the analysis of the observed heterogeneity across individual producers. These theoretical models of industry dynamics include passive learning models that are the primary models that emphasize learning and persistent productivity shocks (Jovanovic, 1982; Hopenhayn, 1992); and active learning models that focus on research and development sources of industry evolution (Ericson and Pakes, 1995; Pakes and Ericson 1998).

In Jovanovic's (1982) model entrepreneurs are uncertain about firms' productivity. As firms produce they acquire noisy information concerning their efficiency. Those who receive systematically negative signals about their productivity exit the industry. Hopenhayn (1992) construct a model where firms receive an idiosyncratic shock each period which then leads them to make a decision about whether to exit or stay in the industry. He provides a characterization and an analysis of the equilibrium steady state. Ericson and Pakes (1998) developed a model where firm efficiency is a stochastic function of the level of investment in research and development. Firms that experience bad luck in their research fall behind the others and are scrapped.

Pakes and Ericson (1998) studied the empirical implications of passive and active learning models in great depth and suggest that the passive learning model fits the retail sector well, while manufacturing shows patterns that suggest active learning models. All these formulations emphasize the role of firm specific factors such as age and size as determinants of firms failure. It is also suggested that industry characteristics (such as sunk costs) are relevant in determining mobility and exit outcomes of firms as well as the size distribution of firms. ${ }^{8}$ Klepper (1996) and Asplund and Nocke (2003) also emphasize the position of the industry on the industry-life cycle and the role of market size. ${ }^{9}$

Work on acquisitions shows that mergers have been the subject of keen interest in an important theoretical and empirical literature. It is often thought that mergers are alternative forms of investment and are commonly used to enter new product or geographic areas, to reallocate assets into the control of the most effective managers/owners and to obtain new knowledge or skills. ${ }^{10}$ Gort's (1969) work focus on the impact of technological shocks on dispersion in valuations and the implications on mergers. He states that mergers are more likely to take place among firms with a higher technical to non technical personnel ratio. Similarly Telser (1987) finds that mergers

\footnotetext{
${ }^{8}$ See also Lambson (1995 and 1998).

${ }^{9}$ For a more detailed literature on empirical and theoretical industrial organization see Caves (1998), Sutton (1997), and Dunne, Roberts and Samuelson (1989a,b).

${ }^{10}$ See Pautler (2001).
} 
were more intense in rapidly growing industries. In addition, mergers are more likely to involve a target in an industry that shows rapid technological change, or a target in a growing industry and an acquirer in a declining one and hence to lead capital to flow faster from declining to expanding sectors. Gort, Grabowski y McGunkin (1985) argue that the indivisibility of management teams creates economics of scope and then companies may try to take over another company and manage it in order to get rid of excess management teams. Shleifer and Vishny (1992) propose that merger waves are driven by liquidity which allows the re-assignment of capital among owners to proceed more smoothly.

Manne (1965) argued that mergers are a means by which well performed firms get the badly managed assets of under performing (targets) firms. In addition he argued that mergers play the same economic role as entry and exit (asset reallocation). Empirical evidence support this idea and suggest that merger transactions involve high market-to-book acquirers purchasing low market-to-book targets. ${ }^{11}$ It is also an extension of Tobin's $Q$ theory of investment, where more profitable firms (high-Q firms) should invest by buying the less efficient firms (low-Q firms). Jovanovic and Rousseau (2001a; 2002 a, b) develop a dynamic model and verify empirically that when Q-dispersion is high merger activity increases. They also show that reallocations of assets among firms by mergers are more likely to occur than purchases of new capital when firms require large capital expansions because of the fixed costs associated with entering the merger market. They discuss why antitrust, regulation policies and globalization (mergers that involve foreign firms) cannot explain the increase in merger activity in the past two decades. They also suggest that fixed costs associated with entering the merger market have also been falling over time.

Though theoretical and empirical models have been proposed to analyze entry and exit issues and large literature have been generated on mergers, there has been relatively little analysis of these processes within a unified framework. Peel and Wilson (1989) argue that the acquisition of a distressed firm should be modeled as a distinct alternative to corporate failure. ${ }^{12}$ Disney et al. (2003) observe that about two-thirds of new entrants exit within five years and approximately half of these are takeovers by other companies under the same ownership groups. Bhattacharjee et al. (2004) present an econometric model in order to analyze how processes that determine bankruptcies and acquisitions depend on macroeconomic environment, and show

\footnotetext{
${ }^{11}$ See Andrade and Stafford (2002).

${ }^{12}$ See also Shary (1991).
} 
that adverse macroeconomic conditions both increase bankruptcies hazard while at the same time decreasing acquisition hazard.

\section{Model.}

In this section we extend the Jovanovic and Rousseau (2002a) model in order to take into account financial frictions and to present a more detailed description and analysis of the market for corporate control endogenizing its equilibrium price. In addition, we characterize the stationary equilibrium of the model as developed by Hopenhayn (1992a).

There exists an industry with a continuum of firms that produce a homogeneous good. The aggregate demand for goods is given by the inverse demand function $P_{t}=D\left(Y_{t}\right)$, assumed to be continuous and strictly decreasing, where $Y_{t}$ is the industry output at period $t$. Firms can accumulate capital $(K \in B \equiv[0, k])$ either buying new machines and equipment (direct investment in unbundled capital goods, denoted as $U$ ) at a price of unity, or they can invest through mergers and acquisitions $(M)$ acquiring capital goods at a price $q$. The unbundled capital good supply price is fixed and there is an endogenous inelastic supply of assembled capital (target firms) as we show later. ${ }^{13}$ Firms production function is given by $y=z K$. Variable $z \in \mathbb{R}_{+}^{0}$ is an idiosyncratic shock that represents the technology of the firm that follows the same Markov process for each incumbent firm, $\operatorname{Pr}\left\{z_{t+1} \leq z^{\prime} / z_{t}=z\right\}=F\left(z^{\prime}, z\right)$.

Before the new shock is realized incumbent firms may exit the industry getting a value $s$ per unit of capital (a scrap value which represents a positive opportunity cost), and then new firms may enter the industry. An entering firm must pay an entry cost $C_{e} \geq 0$. Then, shocks are revealed depending on incumbents and entrants' conditional distribution function $F(\cdot)$ and initial distribution function $G(\cdot)$ respectively. All potential entrants face the same prospects before entry. Then, we denote $K^{e}$ as the level of capital requirements upon entry ( $K^{e}$ is the optimal scale of entrants). If entrants decide to stay in the industry, shocks will evolve according to $F(\cdot)$.

After shocks are revealed price and aggregate production are determined competitively to equate demand and supply. The equilibrium price depend on the quantity of firms producing in the industry and the level of shocks and capital firms show in each period.

We consider a discrete representation of the shocks:

\footnotetext{
${ }^{13}$ This assumption let us, in contrast with Jovanovic and Rousseau (2002a), distinguish what firms are acquired and what firms are dissolved.
} 
Assumption 1. Productivity levels $z$ lie on a finite set of points $S, z \in$ $S \equiv\left\{z^{1}, z^{2}, \ldots, z^{n}\right\}$. The vector of initial probabilities is $g$ and the transition matrix of $z_{t}$ is $T$, where $z^{1}<z^{2}<\ldots<z^{n}$, and $z^{1}=0$ is an absorbing state:

$$
T=\left(\begin{array}{cccccc}
\lambda_{n} & 0 & 0 & . & 0 & 1-\lambda_{n} \\
0 & \lambda_{n-1} & 0 & \cdot & 0 & 1-\lambda_{n-1} \\
\cdot & \cdot & \cdot & \cdot & . & \cdot \\
\cdot & \cdot & \cdot & \cdot & \cdot & \cdot \\
0 & \cdot & \cdot & 0 & \lambda_{2} & 1-\lambda_{2} \\
0 & \cdot & . & 0 & 0 & 1
\end{array}\right), g=\left(\begin{array}{c}
g_{n} \\
g_{n-1} \\
\cdot \\
\cdot \\
g_{2} \\
g_{1}
\end{array}\right)
$$

where $1 \geq \lambda_{i} \geq 0 ; \lambda_{j+1}>\lambda_{j}, j \geq 2$

$$
\text { and } 1 \geq g_{i} \geq 0 ; g_{i}>g_{i+1} ; \lambda_{j}>g_{j}, j \geq 2
$$

with $i=1,2, \ldots, n$.

To clarify, the element $\lambda_{n}$ of the first column corresponds to the transition probability $F\left(z_{t+1}=z^{n} / z_{t}=z^{n}\right)$ and the element $1-\lambda_{n}$ corresponds to $F\left(z_{t+1}=z^{1} / z_{t}=z^{n}\right)$. Then, there is a (first order) stochastic dominance of $F($.) relative to $G($.$) and z$ is positively autocorrelated. These assumptions will help to determine that expected discounted profits are an increasing function of current shock $z$. Matrix $T$ also implies that the life span of a firm is finite. ${ }^{14}$

Furthermore, from direct inspection of transition matrix $T$ assumed, we get some empirical regularities expressed in the next proposition:

Proposition 1 (i) The probability of survival $\left(\lambda_{i}\right)$ is increasing with the initial shock;(ii) the share of high z-firms is increasing in the age of a firm cohort and (iii) there is a skewed distribution of firm sizes (many small firms and a few large firms). ${ }^{15}$

The pair $(z, K)$ is the type of a firm, and the set consisting of all possible such pairs is $Z \times B=\left\{z^{1}, z^{2}, \ldots, z^{n}\right\} \times[0, k]$. Let $\mathcal{A}$ be a set of Borel subsets on $Z \times B$. The total mass of firms in period $t$ is defined by $N_{t}=\Gamma_{t}(A)$, where for any Borel set $A \subset \mathcal{A}, \Gamma_{t}(A)$ is the measure of firms with shocks and capital levels in $A$.

\footnotetext{
${ }^{14}$ These stochastic features of the shocks are consistent with assumptions A.3 and A.4 (recurrence) exposed in Hopenhayn (1992a), and are very important for the existence of a stationary equilibrium with positive entry and exit.

${ }^{15}$ All these implications of the simple structure of the matrix $\mathrm{T}$ we consider are consistent with, although they do not imply, empirical regularities documented in Simon and Bonini (1958), Caves (1998) and Dunne Roberts and Samuelson (1989).
} 
The aggregate production of the industry is:

$$
Y^{s}=\sum_{i=1}^{n} z^{i} \int_{B} K \Gamma\left(z^{i}, d K\right)
$$

Assumption 2. (i) Firms face adjustment costs of capital $K C(u, m)$, where $u \equiv\left(\frac{U}{K}\right)$ and $m \equiv\left(\frac{M}{K}\right) \cdot{ }^{16}$ (ii)As expressed in Jovanovic and Rousseau (2002a), assume that investment through mergers imply a positive fixed cost $(\phi>0)$ and a marginal adjustment cost activity lower than that with direct purchase of new capital goods $\left(c_{u}^{\prime}(u)>c_{m}^{\prime}(m)\right)$. (iii)Let $\phi \equiv \theta n^{M}$, where $n^{M}$ is the number of acquired firms and $\theta$ is a positive parameter. In addition, $\theta$ is big enough to avoid firms acquire more than one firm per period.

As a result, firms have no limit to size due to constant average cost, but they cannot grow infinitely because of the costs of adjustment of capital stock. Furthermore, in assumption 2 (iii) we want to capture the fact that in reality, due to fixed production costs, it is more profitable for a firm to invest in one big firm than buying many small firms in order to achieve a given optimal investment level.

We also assume additive separability of the adjustment cost function:

$$
C(u, m) K=K_{t}\left[I \phi+c_{m}\left(m_{t}\right)+c_{u}\left(u_{t}\right)\right], I=\left\{\begin{array}{lll}
1 & \text { if } & m>0 \\
0 & \text { if } & m=0
\end{array}\right.
$$

In connection to this, Jovanovic and Rousseau define $i \equiv u+m$ as the gross investment rate and suggest that low-i firms will avoid the cost $\phi$ by setting $u \geq 0$ and $m=0$, while firms with big expansions will set $u \geq 0$ and $m>0$. The following equation expresses the per-unit-of-capital adjustment and acquisition costs of $m$ and $u$ and determines the value of $i^{*}$ at which firms are indifferent between setting $(u \geq 0, m=0)$ and $(u \geq 0, m>0)$ :

$$
i^{*}+c_{u}\left(i^{*}\right)=\phi+\min _{m}\left\{\left(i^{*}-m\right)+q m+c_{m}\left(i^{*}-m\right)+c_{u}\left(i^{*}\right)\right\}
$$

The left hand side is the per-unit-of-capital adjustment and acquisition costs related to direct purchase of new capital goods, and the right hand side is the minimized per-unit-of-capital adjustment and acquisition costs of expansions through combinations of $u$ and $m$. The left hand side is lower

\footnotetext{
${ }^{16}$ This is a standard convex cost of adjustment, increasing, differentiable function homogeneous of degree one in $K, E$ and $M$.
} 
when $i$ is small, and the right hand side is lower when $i$ is high, as it is shown in figure 1.

Figure 1 also shows the upward jump in the investment composition while $i$ is rising. The black curve and the black dashing curve indicate the per-unit-of-capital cost of expansions through $u$ exclusively, and through $u$ and $m$, respectively. The grey line shows the evolution of $u$, while the grey dashing line corresponds to $m$. The figure shows that small expansions come exclusively through $u$ while great expansions show combinations of $u$ and $m$ where the share of $m$ is increasing in $i$.

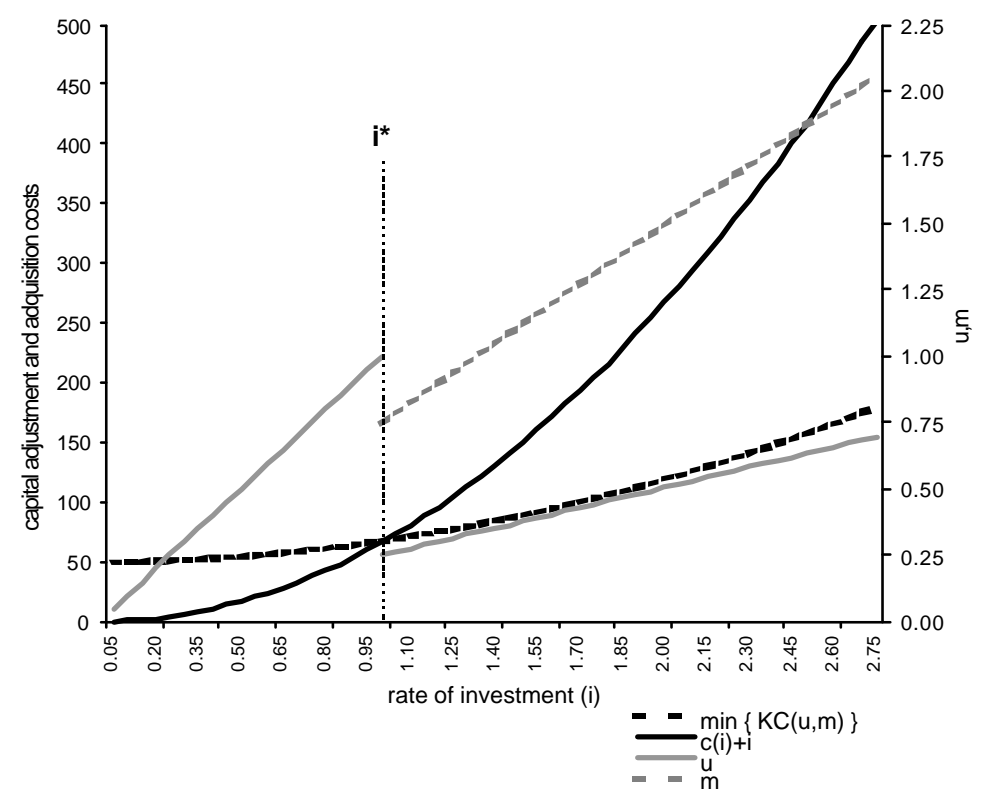

Figure 1.

Jovanovic and Rousseau (2002a) document that this indifference point has fallen over time, and they suggest that a decline in the parameter $\phi$ explains this fact. Our paper provides a more detailed framework in order to analyze an alternative theoretical explanation, keeping $\phi$ constant over time.

Incumbent firms maximize expected discounted profits and accumulate capital according to $K_{t+1}=(1-\delta) K_{t}+U_{t}+M_{t}$. The optimization problem of the firm is:

$$
\mathcal{L}=V_{t}\left(z_{t}, P_{t}, K_{t}\right)=\max _{\left\{U_{t+s}\right\}_{s=0}^{\infty}\left\{M_{t+s}\right\}_{s=0}^{\infty}} \pi_{t}+E_{t}\left[\sum_{s=1}^{\infty} \beta^{t+s-1} \pi_{t+s}\right]
$$


where

$$
\pi_{t}=\left\{P_{t} z K_{t}-K_{t}\left[I \phi+c_{m}\left(m_{t}\right)+c_{u}\left(u_{t}\right)\right]-U_{t}-q M_{t}\right\}
$$

subject to

$$
K_{t+1}=(1-\delta) K_{t}+U_{t}+M_{t}
$$

This problem can be rewritten in a recursive fashion where firms maximize the expected discounted value of dividends given the possibility to exit the industry (getting $s$ per unit of capital). ${ }^{17}$

$$
\begin{aligned}
& V_{t}\left(z_{t}^{i}, P_{t}, K_{t}\right)=K_{t} Q_{t}\left(z_{t}^{i}, P_{t}\right)=\max _{U \geq 0, M \geq 0}\left\{P_{t} z_{t}^{i} K_{t}-K_{t}\left[I \phi+c_{m}\left(m_{t}\right)+c_{u}\left(u_{t}\right)\right]\right. \\
& \left.-U_{t}-q M_{t}+\left[K_{t}(1-\delta)+U_{t}+M_{t}\right] Q_{t}^{*}\right\}
\end{aligned}
$$

where

$$
Q_{t}^{*}\left(z_{t}^{i}, P_{t}\right)=\beta_{t} \sum_{j} \max \left\{s, Q_{t+1}\left(z_{t+1}^{j}, P_{t+1}\right)\right\} T_{i j}
$$

and $i, j=1,2, \ldots, n$, and $T_{i, j}$ is the $i, j$ element of $T$.

Incumbent firms decide whether to exit or to stay in the industry before next period's shock is revealed. In equilibrium firms exit the industry whenever $z$ falls below a reservation value $z^{x}$, as exposed in Hopenhyan (1992a).

$$
z_{t}^{x}=\inf \left\{z^{i} \in S: \sum_{j} Q_{t+1}\left(z_{t+1}^{j}, P_{t+1}\right) T_{i j} \geq s\right\}
$$

This boundary $z_{t}^{x}$ is the lowest level of productivity that will enable the firm to have, over future periods, positive discounted expected profits. We assume that firm exit decisions does not depend on $q$ because of myopia. They do not go to the market for corporate control until they fail. Then, they base their exit decisions only on $s$. This assumption avoid us dealing with possible mergers between incumbent firms, which would complicate considerably the analysis.

We have shown that firm value is linear in $K$, and that firm survival depends on $z$ but not on $K$. Then, it can also be shown that:

\footnotetext{
${ }^{17}$ As output function and capital adjustment cost are homogeneous of degree one in $K, M$ and $E$, the aggregation condition of Hayashi and Inoue holds and then firm's value is lineal in $K$, that is $V\left(z_{t}, P_{t}, K_{t}\right)=K_{t} Q\left(z_{t}, P_{t}\right)$, and firm's value per unit of capital $Q\left(z_{t}, P_{t}\right)$ does not depend on firm's capital level (see the citation of Hayashi and Inoue (1991) in Jovanovic and Rousseau (2002a) for details).
} 
Proposition 2 The average size of firms in a given age cohort increases over time. ${ }^{18}$

Proof. Let $y_{h}$ denote the output of firms in a given cohort of age $h, n_{t}^{e}$ the mass of entrants in period $t$ and $\rho_{h}$ the proportion of firms in the cohort that are still in the industry after $t$ periods,

$$
\rho_{h}=\sum_{i=x}^{n}\left(\lambda_{i}\right)^{h} g_{i}
$$

where $g_{i}$ is the $i$ element of the vector $g$ of initial probabilities. Notice that $\rho_{h}$ is decreasing in $x$. The average size of firms in a given age cohort $h>0$ is

$$
\bar{y}_{h}=\frac{\sum_{i=x}^{n}\left(\lambda_{i}\right)^{h} g_{i} z^{i} \int_{B} K \Gamma\left(z^{i}, d K\right)}{\sum_{i=x}^{n}\left(\lambda_{i}\right)^{h} g_{i}}
$$

and, consequently, proposition $1(i)$ implies that $\bar{y}_{j}$ is increasing with the age of a cohort.

Assumption 3. All potential entrants have a the same wealth level $W<K^{e}$ and have to borrow $\left(K^{e}-W\right)$ to finance their business project, at the interest rate $r^{e}$. And we define $C_{e}=W+\left(K^{e}-W\right)\left(1+r^{e}\right)$.

Hence, the start-up capital requirements constitutes a cost of entry because entrepreneurs must finance greater amounts than incumbents and the cost of capital is higher for entrants than for incumbents because of the interest rate $r^{e} .{ }^{19}$ This can be thought as a reduced form representation of capital market imperfections (a problem of asymmetric information about entrepreneurs' survival probabilities), then expensive loans are granted to new firms.

We assume that entering capital takes a period to become active. New firms will enter the industry until their expected discounted value is equal

\footnotetext{
${ }^{18}$ This is another empirical fact documented in Dunne, Roberts and Samuelson (1989). ${ }^{19}$ Cooley and Quadrini (1998) present empirical evidence that small and younger firms take on more debt. To simplify, we assume that incumbent firms have current profits big enough to cover the total costs of the efficient investment rate according to $z^{i}$.
} 
to the cost of entry $C e$. Their expected discounted value is:

$$
V_{t}^{e}\left(P_{t}\right)=K^{e} \beta \sum_{i} \max \left\{s, Q_{t+1}\left(z_{t+1}^{i}, P_{t+1}\right)\right\} g_{i}-\overbrace{W+\left(K^{e}-W\right)\left(1+r^{e}\right)}^{C_{e}}]
$$

The evolution of the number of firms in the industry is given by the following law of motion:

$$
\sum_{z} \int_{B} \Gamma_{t+1}\left(z^{i}, d K\right)=\sum_{j} \sum_{i>x} T_{i j} \int_{B} \Gamma_{t}\left(z^{i}, d K\right)+n_{t}^{e}
$$

More specifically, the left hand side express the mass of firms in period $t+1$. The right hand side is the number of incumbent surviving firms plus new entrants.

Defining the transition operator $P_{x}^{\prime}$ for the exit rule $z^{x}$ in the same way as in Hopenhayn (1992a), the law of motion of the number of firms expressed in matricial notation is defined $\mathrm{as}^{20}$ :

$$
\Gamma_{t+1}=P_{x}^{\prime} \Gamma_{t}+n_{t}^{e} g
$$

We have assumed that shocks are positively autocorrelated. Thus, this fact let us derive the following result.

Proposition 3 (Jovanovic and Rousseau, 2001a) If the $z$ shocks are positively autocorrelated, then firm's investment is increasing in $z$ and large firms tend to grow faster.

Proof. See Jovanovic and Rousseau (2001a), proposition 1 and corollary 2 .

The intuition is simple. If $z$ is positively autocorrelated, the right-hand side of (8) depends on $z$ and from the first order conditions ${ }^{21} M$ and $U$ are increasing in $z$. Therefore, as $Q\left(z_{t}, P_{t}\right)$ is increasing in $z$, high- $z$ firms will show the largest expansions. In addition, higher- $z$ firms will tend to be larger.

\footnotetext{
${ }^{20}$ See appendix 7.1 for details.

${ }^{21}$ See appendix 7.2 for details.
} 


\section{Stationary equilibrium.}

In this section we characterize the stationary equilibrium concept as developed by Hopenhayn (1992a). Given any distribution of firms $\Gamma_{t}$ there exist a unique aggregate output $Y_{t}$ and prices $P_{t}^{*}\left(\Gamma_{t}\right)$ and $q_{t}^{*}\left(\Gamma_{t}\right)$ that satisfy market clearing condition for goods $P_{t}^{*}=D\left(Y_{t}^{s}\left(\Gamma_{t}^{*}, P_{t}^{*}\left(\Gamma_{t}^{*}\right)\right)\right.$, and market clearing conditions for bundled and unbundled capital goods:

$$
q_{t}^{*}=D^{M}\left(\sum_{i=x}^{n} M_{t} \int_{B} \Gamma_{t}\left(z^{i}, d K\right)\right) ; 1=D^{U}\left(\sum_{i=x}^{n} U_{t} \int_{B} \Gamma_{t}\left(z^{i}, d K\right)\right)
$$

where $D^{M}$ and $D^{U}$ are inverse demand functions for firms in the acquisition market and for new capital goods, respectively. In addition, the stationary equilibrium for the industry can be defined by the condition $\Gamma_{t}=\Gamma^{*}$, where the following equations must be satisfied:

$$
\begin{gathered}
\sum_{j} Q_{t+1}\left(z_{t+1}^{j}, \Gamma^{*}\right) T_{i j}=s \quad \text { with } i=x \\
K_{t}^{e}\left\{\beta \sum_{i} \max \left\{s, Q_{t+1}\left(z_{t+1}^{i}, \Gamma^{*}\right)\right\} g_{i}\right\}=C e \\
\Gamma^{*}=n^{e *}\left(1-P_{x^{*}}\right)^{-1} g \\
{\left[c_{u}^{\prime}\left(u_{t}\right)+1\right]=\beta_{t} \mathrm{E}_{t}\left[\max \left\{s,\left[P_{t+1} z_{t+1}+C^{K}(\cdot)+(1-\delta)\left(c_{u}^{\prime}\left(u_{t+1}\right)+1\right)\right]\right\}\right]} \\
{\left[c_{m}^{\prime}\left(m_{t}\right)+q\right]=\beta_{t} \mathrm{E}_{t}\left[\max \left\{s,\left[P_{t+1} z_{t+1}+C^{K}(\cdot)+(1-\delta)\left(c_{m}^{\prime}\left(m_{t+1}\right)+q\right)\right]\right\}\right]}
\end{gathered}
$$

Equation (13) implies that the exit rule is chosen optimally. Condition (14) assures that new firms will enter the industry until the expected discounted value is equal to the cost of entry. The last two conditions (16) and (17) are the Euler equations that characterize the optimal investment decisions. ${ }^{22}$

Condition (15) is the stationary distribution of the number of firms coming from (12), and states that the distribution sequences are consistent with

\footnotetext{
${ }^{22}$ See appendix 7.2 for details.
} 
the law of motion generated by the equilibrium exit rule and the mass of entrants, respectively. Based on this equation assume a measure $\Gamma=R\left(z^{x}, n^{e}\right)$, jointly continuous, decreasing in $z^{x}$, and increasing in $n^{e} .{ }^{23}$ As a result, conditions (13) and (14) can be expressed as follows:

$$
\begin{gathered}
\text { (exit rule) } \sum_{j} Q_{t+1}\left(z_{t+1}^{j}, R\left(z^{x}, n_{1}^{e}(x)\right)\right) T_{i j}=s \quad \text { with } i=x \\
\left(\text { entry rule) } K _ { t } ^ { e } \left\{\beta \sum_{i} \max \left\{s, Q_{t+1}\left(z_{t+1}^{i}, R\left(z^{x}, n_{2}^{e}(x)\right)\right\} g_{i}\right\}=C e\right.\right.
\end{gathered}
$$

Adding up, for an exit rule $z_{t}^{x}$, we define $n_{1}^{e}$ and $n_{2}^{e}$ as the number of entrants needed so that the exit rule $z^{x}$ is optimal (equation 18), and the expected discounted value of entrants is equal to the cost of entry (equation 19), respectively. Figure 2 portrays functions $n_{1}^{e}$ and $n_{2}^{e}$. For an exit rule $z_{t}^{x}$, the function $Q\left(z_{t+1}, R\left(z_{t}^{x}, n_{t}^{e}\left(z_{t}^{x}\right)\right)\right.$ has a maximum at $z^{n}$ for all $n^{e}>0$, where $n_{1}^{e}\left(z^{n}\right)>n_{2}^{e}\left(z^{n}\right)$ from direct inspection of (18) and (19). Hopenhayn(1992a,b) establishes the conditions under which there exists a unique stationary equilibrium (there exist a point such that $n_{1}^{e}<n_{2}^{e}$, and curves $n_{1}^{e}$ and $n_{2}^{e}$ intersect only once). ${ }^{24}$

\footnotetext{
${ }^{23}$ For a proof see Lemmas 4 and 5 in Hopenhayn (1992a).

${ }^{24}$ Basically, the existence of stationary equilibrium with positive entry and exit requires the existence of a stopping rule with finite expectation and a mass of entrants such that for the stationary prices that correspond to the associated invariant distribution this stopping rule is optimal and the expected discounted profits of entrants are equal to the cost of entry. See the appendix 7.3 for details.
} 


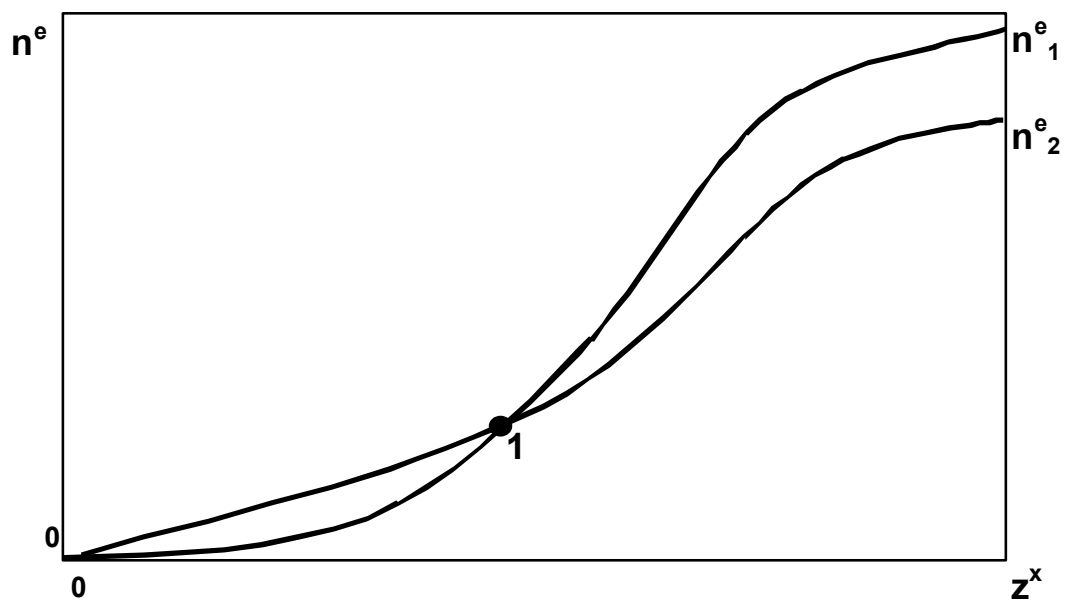

Figure 2. (From Hopenhayn, 1992a).

\subsection{Equilibrium in the market for corporate control.}

Based on our additional assumptions respect to Jovanovic and Rousseau (2002a) model, in this section we present a detailed description of the market for corporate control that, in contrast with Jovanovic and Rousseau, allow us to characterize exiting firms that are dissolved and exiting firms that go bankrupt and are acquired by successful incumbents.

The lowest level of productivity that enable the firm to stay in business is $z^{x}$. Each period firms with different levels of $K$ and $z<z^{x}$ exit. Hence, there is a measure of exiting firms defined for each capital size and this measure constitutes the supply of firms in the acquisition market which is endogenous because $z^{x}$ is endogenous. As a result, there is an endogenous inelastic supply of assembled capital (target/exiting firms) per period, $\sum_{i=1}^{x-1} K_{t} \int_{B} \Gamma\left(z^{i}, d K\right)$, as it is portrayed in figure 3 , quadrant 1 , for each size of capital.

Denote by $z^{m}$ the lowest efficiency level at which the firm invest through mergers. Furthermore, $z^{m}$ corresponds to the lowest productivity shock that yields an investment rate $i$ higher than the indifference investment rate $i^{*}$ in equation (3) (denoted by the vertical line in Figure 1), which is determined by the adjustment cost function parameters and input prices. As the price for new capital goods is determined competitively in the economy, while 
bundled capital goods are specific to the industry ${ }^{25}$ and are determined competitively in the industry, the former is exogenous (and we normalized it to 1 ) and the latter $(q)$ is endogenous to the industry. The latter determines the slope of the per-unit-of-capital cost curve (black dashing curve in figure 1 ) of expansions through combinations of $U$ and $M$. Therefore, $q$ determines the cutoff level $z^{m}$ and the mass of firms entering the acquisition market. ${ }^{26}$ Then, it shapes the demand for corporate control.

Assuming an adjustment cost function $c_{m}\left(m_{t}\right)=m^{2} / 2 \alpha$, from the first order condition ${ }^{27}$ we have the investment rate through $m$ defined by $m=$ $\alpha\left[Q_{t}^{*}\left(z^{i}, P\right)-q\right]$ that is portrayed in figure 3 , quadrant 3 . In fact, there is a map of parallel lines from that of the highest- $z$ firm $\left(m\left(z^{n}, q\right)\right)$ until the less efficient firm that show $m>0$ (denoted by $m\left(z^{m}, q\right)$ ).

Notice that $M=m K$. Hence, in quadrant 2 the graph reflects the relation between $m$ and $M$ by a line which slope is the capital stock of the firm. At price $q$ the largest and most efficient firm has an investment rate through $m$ showed by point $A$ and an absolute acquisition investment $M$ at point $A^{\prime}$ which intersect the maximum capital stock line $\bar{K} \cdot{ }^{28}$ While a firm defined by a pair $\left(z^{n}, K^{e}\right)$ is situated at point $A^{\prime \prime}$. On the other hand, $z^{m}$-firms that have a maximum capital stock $K<\bar{K}$ (defined by the grey dashing line) is situated at point $B^{\prime}$, while firms defined by the pair $\left(z^{m}, K^{e}\right)$ are indicated in point $B^{\prime \prime}$.

Given a price $q$, the aggregate demand for corporate control is:

$$
\sum_{i=x}^{n} M_{t} \int_{B} \Gamma_{t}\left(z^{i}, d K\right)
$$

In quadrant 1 , between points $B^{\prime \prime \prime}$ and $A^{\prime \prime \prime}$ (pointed out with an $M$ ), it is shown the measure $\Gamma\left(z^{i}, K\right)$ with $z^{n} \geq z^{i} \geq z^{m}$ and $K^{e} \geq K \geq \bar{K}$. It is the number of firms that constitutes the demand for corporate control, for each size of capital, at a given price $q$.

\footnotetext{
${ }^{25}$ If you want to sell bundled assets outside the industry you have to disassemble them.

${ }^{26}$ To clarify, looking at figure 1 , a decrease in $q$ leads to a lower slope of the black dashing curve (the per-unit-of-capital cost of expansions through optimal combinations of $U$ and $M)$. Then the rate of investment at which this curve intersects the black curve (the per-unit-of-capital cost of expansions through $U$ exclusively) decreases, leading to a lower rate of investment $i^{*}$ (that corresponds to a lower $z^{m}$ shock) at which firms are indifferent between entering the acquisition market and staying out of it.

${ }^{27}$ See equation (24) in appendix 7.2.

${ }^{28}$ We define $\bar{K} \in B$ as the maximum capital stock a firm can achieve given the maximum finite life span of a $z^{n}$-firm, the initial firm's capital stock $K^{e}$ and the adjustment cost functions.
} 
In equilibrium, the demand for bundled capital goods (acquisitions), defined by the distribution of the number of firms in the interval $\left[B^{\prime \prime \prime}, A^{\prime \prime \prime}\right]$, is equal to the upper tail of the inelastic supply of target firms per size (the mass of bankrupt firms). ${ }^{29}$ Furthermore, denote by $D^{M}$ the aggregate inverse acquisition demand function. Then, the expression for the acquisition market clearing price condition is:

$$
q_{t}=D^{M}\left(\sum_{i=x}^{n} M_{t} \int_{B} \Gamma_{t}\left(z^{i}, d K\right)\right)
$$

Then, looking at figure 3 , in equilibrium firms with size in the interval $\left[B^{\prime \prime \prime}, A^{\prime \prime \prime}\right]$ are acquired, while those with size $K<B^{\prime \prime \prime}$ are dissolved and get $s$ per unit of capital.

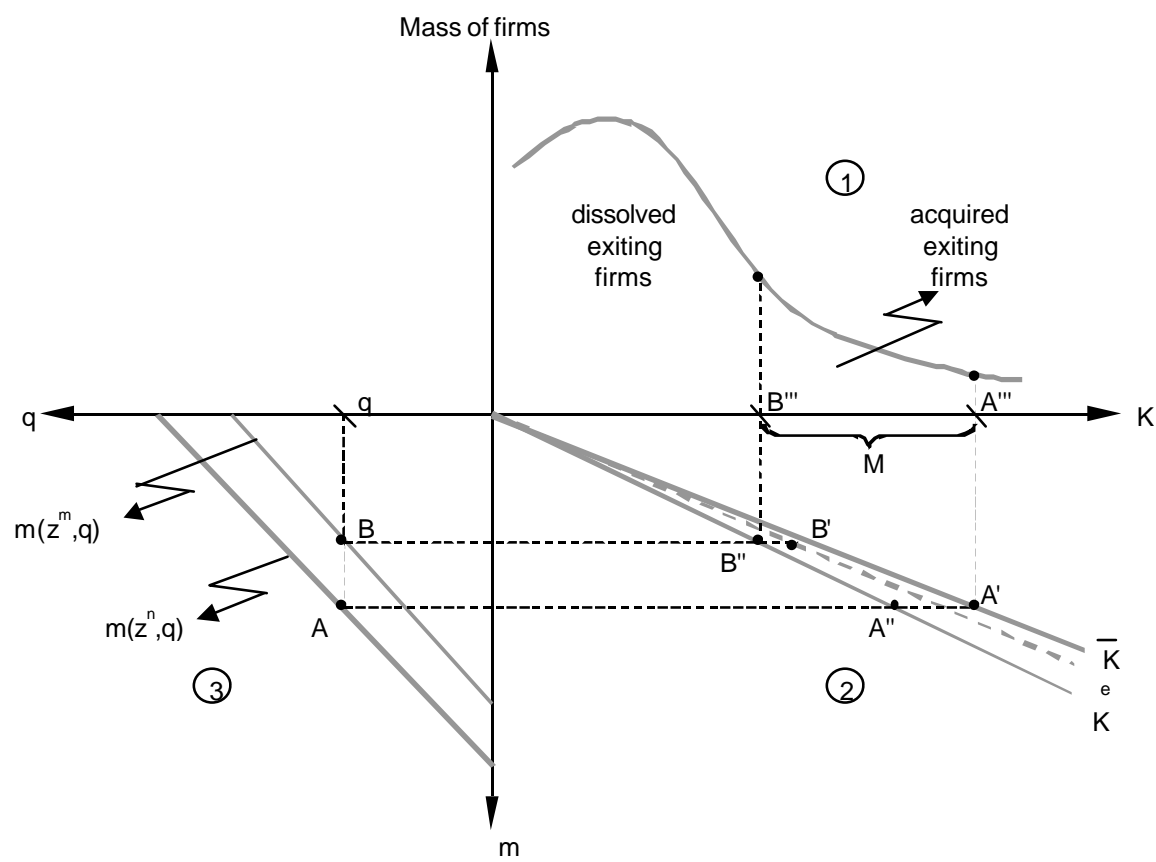

Figure 3.

\footnotetext{
${ }^{29}$ In fact, there should be a sequence of prices $q^{i}$ determined by the relative shortage of exiting firm of each size. But in order to simplify we assume that the properties of the stochastic process for shocks and the properties of the adjustment cost functions make prices $q^{i}$ collapse to only one price $(q)$. In other words, price $q$ clear all these markets (the market for corporate control for each size).
} 
As a result, large exiting firms qualify ${ }^{30}$ to participate in the acquisition market becoming target firms (potential acquirees) that find the offers from acquirers to be higher than the scrap value $s$, while relative small firms are dissolved and get $s$ per unit of capital.

\section{Comparative statics.}

In this section we analyze the effect that changes in some relevant parameters have on the stationary equilibrium above defined. In particular we make two exercises according to our suggestion about the role that liquidity shocks play on merger activity. We analyze the mechanism by which an increase in aggregate liquidity may have an impact on investment through mergers.

$A$ reduction in the entry cost, $C_{e}$. Assume that due to a "liquidity" shock, the economy becomes more financially developed and the credit supply increase having a positive impact (a reduction) in the cost of capital $r^{e}$ of entrepreneurs. Figure 4 depicts the effect of a decrease in $C_{e}$ on the stationary equilibrium. As it is analyzed in Hopenhayn (1992a), a lower cost of entry has a selection effect and a price effect. First, we examine the former. Accordingly, by looking at equilibrium conditions (18) and (19) a decrease in $C_{e}$ shifts curve $n_{2}^{e}$ upwards. Entry must increase in order to balance the discounted profits of entrants with a lower $C_{e}$ in equation (19). Since curve $n_{1}^{e}$ is increasing this implies that the equilibrium $z^{x}$ increases and so does $n^{e}$.

\footnotetext{
${ }^{30}$ To reach a capital scale (exiting firm size) according to the optimal investment level through mergers that incumbent firms are looking for at a given price $q$.
} 


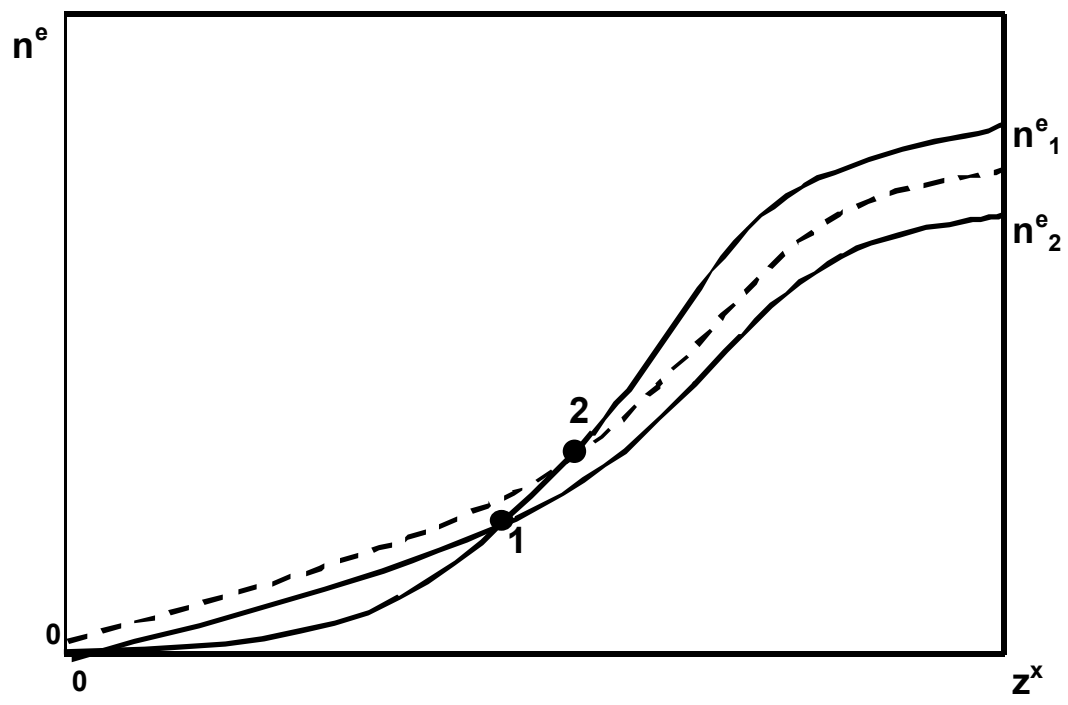

Figure 4.

The increase in equilibrium $z^{x}$ and $n^{e}$ values implies an increase in the intensity of market selection (higher turnover rate of firms) because of the lower barrier to entry of new firms and because the higher $z^{x}$ increases the exit rate. Then, a higher mass of firms (in particular, a higher number of large firms) exit the industry, expanding the supply of target firms in the acquisition market (see the mass of exiting firms -dashing curve- in figure 5 , quadrant 1 ). Then, this excess of supply of target firms induces a negative change in $q$ (the slope of the per-unit-of-capital cost curve -black dashing curve of figure 1- through optimal combinations of $U$ and $M$ ) and, as mentioned before, it determines a reduction in the cutoff level $z^{m}$ increasing the mass of firms entering the acquisition market. ${ }^{31}$ In addition, it changes the composition of firms' investment increasing the share of mergers. A fraction of firms with lower shocks become acquirers, and this is reflected by the dashing line in quadrant 3 , figure 5 . Then, the least efficient firm with the lowest capital level $K^{e}$ is located at point $B_{2}$ in quadrant 1 , while more efficient acquirers increase their investment scale through mergers (for

\footnotetext{
${ }^{31}$ As it was mentioned in the previous section, by looking at equation 3 and figure 1 , a decrease in $q$ leads to a lower rate of investment $i^{*}$ (that corresponds to a lower $z^{m}$ shock) at which firms are indifferent between entering the acquisition market and staying out of it.
} 
example, firms defined by the pair $\left(z^{n}, \bar{K}\right)$ is now situated at point $\left.A_{2}\right)$.

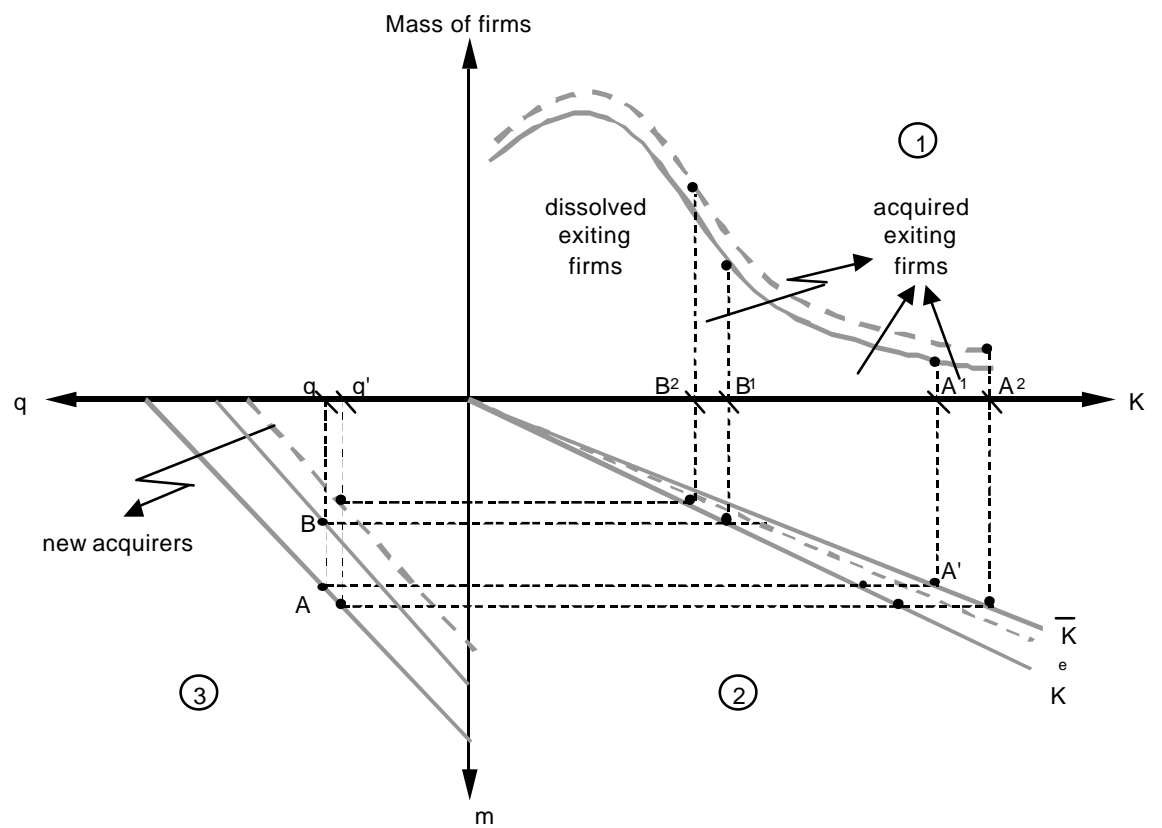

Figure 5.

But there is also a price effect: ${ }^{32}$ output price decreases with the lower $C_{e}$ leading to a reduction in $Q\left(z^{i}, P\right)$ and $m$.

The net effect depends on the strength of each of these effects that are determined by the properties of the stochastic process for idiosyncratic shocks. By proposition 1(iii) we know that due to the skewed frequency distribution of firm efficiencies the elasticity of exit rate to a positive change in $z^{x}$ (that represents an expansion of the acquisition market supply) is higher than the elasticity of the (lower) measure of acquirers (demand for acquisitions) to a positive change in $z^{m}$ (due to a reduction in the output price). ${ }^{33}$ Then, it can be thought as if there are more firms exiting and approximately the same number of acquirers. In addition, in the market for corporate control the

\footnotetext{
${ }^{32}$ By looking at equation (19), if $C_{e}$ decreases, to match the lower entry cost discounted profits need to be lower. Then, the long run output price must decrease. See Hopenhayn (1992a), pp. 1142 for details.

${ }^{33} \mathrm{~A}$ reduction in the output price leads to lower $Q\left(z^{i}, P\right)$. Hence, the investment rate of all firms decreases. Then, a higher shock $z^{m}$ corresponds to the same $i^{*}$ (rate of investment at which firms are indifferent between entering the acquisition market and staying out of it).
} 
demand elasticity is higher than that of the supply (that, as we mentioned before, is inelastic). Then, a simultaneous inelastic supply expansion with a demand contraction leads to more mergers at lower prices $(q)$.

As a result, a reduction in the cost of entry, $C_{e}$, leads to higher turnover rate that induces a decline in $q$ and an increase in mergers.

An increase in the outside industry opportunity cost, s. Assume there is an increase in the opportunity cost $s$. For example, outside opportunities may rise because of a liquidity shock that reduces the cost of entry in other industries, increasing the mobility of resources among different markets.

Hence, according to equations (18) and (19), the curve $n_{1}^{e}$ shifts downwards (to match the higher opportunity cost, $s$, discounted profits must rise in order to keep incumbent firms indifferent between exiting and staying in the industry) resulting in higher values for $z^{x}$ and $n^{e}$. As in the previous case, this would imply a higher rate of turnover. The increase in $z^{x}$ induces a larger proportion of firms to fail leading to an expansion in the inelastic supply for each size of target firms in the acquisition market (again, this is reflected by the higher mass of exiting firms -dashing curve- in figure 5 , quadrant 1). Therefore, more high-capital firms qualify to participate in the acquisition market becoming potential acquirees. Then, price $q$ drops down.

In contrast with the previous case, there is no effect on output price because all parameters in equation (19) remain the same. Then, as in the previous case, a reduction in $q$ determines a fall in the cutoff level $z^{m}$ that changes the composition of firms' investment increasing the share of mergers and increasing the mass of firms entering the acquisition market. Therefore, a proportion of firms with lower shocks become acquirers (as it is pointed out by the dashing line in quadrant 3, figure 5) and all acquirer firms invest more through $M$. As a result, the number and scale of mergers increases.

Adding up, as it was shown in the previous comparative static exercises, in our model merger waves are likely to be driven by aggregate liquidity shocks.

\section{Final Remarks.}

We develop a theoretical model within which to study factors affecting variables such as entry, exit and investment through direct unbundled capital good purchase and mergers. The model we build is an extension of a modified version of Jovanovic and Rousseau (2002) model that introduces financial frictions, describes the market for corporate control and endogenizes 
its equilibrium price, and develops a stationary equilibrium à la Hopenhayn (1992).

The simple theoretical framework developed in this paper is just an attempt to provide an alternative explanation in order to help to understand some aspects of the complex reality. So, the distance between the real economy and our results are proportional to the quantity and quality of all assumptions made in our model. Notwithstanding, as far as there is no theoretical explanation for the questions expressed in this context from which different results will be obtained, the conclusions found are considered to be worthy.

This work contributes to the literature by providing a unified framework where the turnover rate of firms and mergers processes are codetermined, suggesting another explanation to many empirical regularities and describing one more mechanism through which aggregate liquidity shocks may affect merger activity. The results suggest that due to asymmetric information about entrepreneur's survival probabilities aggregate liquidity shocks contribute to codetermine the turnover rate of firms and investment levels through mergers.

Empirical evidence suggests that economies became more financially developed in the last decades ${ }^{34}$ leading to an improvement in the matching efficiency between risky investors and entrepreneurs. As a result, the sources of financial capital for entrepreneurs have grown. In our model this phenomenon (a fall in entrepreneurs financing costs) leads to a reduction in the costs of entry increasing the turnover rate of firms and mergers activity. Furthermore, it provides an alternative theoretical explanation to the evidenced increase in merger activity and the change in firms' investment composition over the past two decades. Merger waves are likely to be driven by aggregate liquidity shocks.

\footnotetext{
${ }^{34}$ See Damodaran (1999) and Effenberg (2003).
} 


\section{Appendix.}

\subsection{Law of motion of the number of firms.}

In order to save space, consider the special case of $n=4$. Assume $z \in$ $S \equiv\left\{z^{1}, z^{2}, z^{3}, z^{4}\right\}$,with $z^{1}<z^{2}<z^{x}<z^{3}<z^{4}$. Then, equation (12) is expressed as follows:

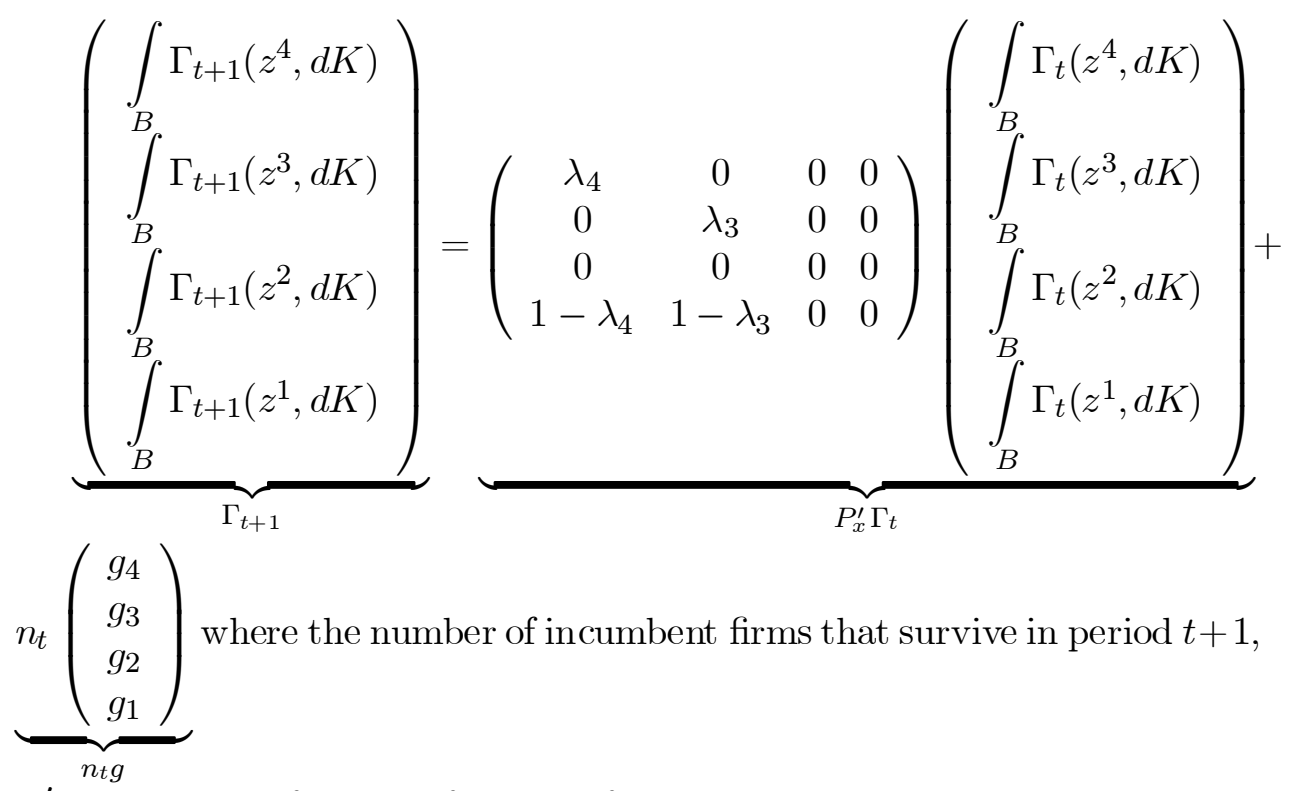

$P_{x}^{\prime} \Gamma_{t}$, is derived from the following fact:

$$
\begin{aligned}
& \left(P_{x}^{\prime} \Gamma_{t}\right)^{\prime}=\Gamma_{t}^{\prime} P_{x}= \\
& \left(\int_{B} \Gamma_{t}\left(z^{4}, d K\right) \int_{B} \Gamma_{t}\left(z^{3}, d K\right) \int_{B} \Gamma_{t}\left(z^{2}, d K\right) \int_{B} \Gamma_{t}\left(z^{1}, d K\right)\right)\left(\begin{array}{cccc}
\lambda_{4} & 0 & 0 & 1-\lambda_{4} \\
0 & \lambda_{3} & 0 & 1-\lambda_{3} \\
0 & 0 & 0 & 0 \\
0 & 0 & 0 & 0
\end{array}\right)
\end{aligned}
$$

\subsection{Demand for capital, Tobin's Marginal Q and Euler equa- tions.}

In this section we derive the first order conditions of the incumbent firm's problem. From the Bellman equation we have:

$$
\begin{gathered}
u_{t}:\left[c_{u}^{\prime}\left(u_{t}\right)+1\right]-Q_{t}^{*}=0 \\
m_{t}:\left[c_{m}^{\prime}\left(m_{t}\right)+q\right]-Q_{t}^{*}=0
\end{gathered}
$$


From the first order conditions one can derive the demands for equipment and mergers:

$$
\begin{aligned}
& u_{t}=c_{u}^{\prime}\left[\left(Q_{t}^{*}-1\right)\right]^{-1} \\
& m_{t}=c_{m}^{\prime}\left[\left(Q_{t}^{*}-q\right)\right]^{-1}
\end{aligned}
$$

We define a proxy Tobin's Marginal $Q$ (measured at the end of period $t$ or at the beginning of period $t+1$ ) as the increase in firms' value (in period $t+1)$ that would result from an additional unit of installed capital, $Q_{t}=\left(\frac{\partial V}{\partial K}\right)_{t+1}$. The envelope condition is:

$$
\begin{gathered}
\left(\frac{\partial V(z, P, K)}{\partial K}\right)_{t}=Q_{t-1}= \\
\{P_{t} z_{t} \underbrace{-\left[I \phi+c_{m}\left(m_{t}\right)+c_{u}\left(u_{t}\right)\right]+\frac{M}{K} c_{m}^{\prime}\left(m_{t}\right)+\frac{U}{K} c_{u}^{\prime}\left(u_{t}\right)}_{C^{K}(.)}\}+(1-\delta) Q_{t}^{*}
\end{gathered}
$$

This equation one period ahead is:

$$
Q_{t}=\left\{P_{t+1} z_{t+1}+C^{K}(\cdot)\right\}+(1-\delta) Q_{t+1}^{*}
$$

Combining this equation and the FOCs to eliminate $Q_{t}$ and $Q_{t}^{*}$ from equation (14) $Q_{t}^{*}(\cdot)=\beta_{t} \sum_{j} \max \left\{s, Q_{t+1}(\cdot)\right\} T_{i j}$, yields the Euler equations:

$$
\begin{aligned}
& {\left[c_{u}^{\prime}\left(u_{t}\right)+1\right]=} \\
& \beta_{t} \sum_{j} \max \left\{s,\left[P_{t+1} z_{t+1}^{j}+C^{K}(\cdot)+(1-\delta)\left(c_{u}^{\prime}\left(u_{t+1}\right)+1\right)\right]\right\} T_{i j} \\
& {\left[c_{m}^{\prime}\left(m_{t}\right)+q\right]=} \\
& \beta_{t} \sum_{j} \max \left\{s,\left[P_{t+1} z_{t+1}^{j}+C^{K}(\cdot)+(1-\delta)\left(c_{m}^{\prime}\left(m_{t+1}\right)+q\right)\right]\right\} T_{i j}
\end{aligned}
$$




\subsection{Existence of equilibrium with positive entry and exit..$^{35}$}

In order to guarantee an equilibrium with positive entry and exit so that the equilibrium price remains constant over time, we need to make an additional assumption.

Assumption 3. The sequence $\rho_{h} \bar{y}_{h}$ is decreasing with the age $h$ of a firm cohort.

Then, the total output of a cohort of firms of age $h$ that entered into the industry in period $t$ is $n_{t}^{e} \rho_{h} \bar{y}_{h}$. According to assumption 3 the contribution to the total production of a given cohort of firms decreases over time. ${ }^{36}$

As $V^{e}(\cdot)$ is strictly increasing in $P$, in equilibrium there is a unique price $P^{*}$ so that $V^{e}\left(P^{*}\right)=C e$, and a given sequence of entries that satisfies the following equation for the total output of the industry:

$$
Y_{t}=n_{t}^{e} \sum_{i=1}^{n} z^{i} K^{e} g_{i}+\sum_{h=0}^{t-1} n_{h}^{e} \rho_{h} \bar{y}_{t-h}
$$

The first term on the right hand side is the entrant's output contribution to the industry production, and the second term is the incumbent's output contribution to the industry production, both in period $t$.

By assumption $3 \rho_{h} \bar{y}_{h}$ is a decreasing sequence, then we have:

$$
\sum_{h=0}^{t-1} n_{h}^{e} \rho_{h} \bar{y}_{t-h}<\sum_{h=0}^{t-1} n_{h}^{e} \rho_{h} \bar{y}_{t-h-1}=Y_{t-1}
$$

Adding up, given that $P^{*}$ satisfies the condition $V^{e}\left(P^{*}\right)=C e$, and given stationarity $Y_{t}=Y_{t-1}$, every period the production of incumbent firms is not big enough to equal demand at this equilibrium price, so there is room for entrants to supply this production gap, and this guarantees that $n_{t}^{e}>0$ $\forall t$ and thus the equilibrium is interior.

\footnotetext{
${ }^{35}$ This section is an adaptation of Hopenhayn (1993).

${ }^{36}$ This assumption is consistent with empirical regularity (see Dunne, Roberts and Samuelson, 1989a).
} 


\section{References}

[1] Andrade G. and Stafford E. (2002). "Investigating the Economic Role of Mergers.", Journal of Corporate Finance, 161, pp. xxx-xxx.

[2] Asplund and Nocke (2003). "Firm Turnover and Imperfectly Competitive Markets.", mimeo, University of Pennsylvania.

[3] Bhattacharjee, Higson, Holly and Kattuman (2004). "Macroeconomic Conditions and Business Exit: Determinants of Failure and Acquisitions of UK Firms.", DAE Working Paper 0206, Department of Applied Economics, University of Cambridge.

[4] Cabral Luís (1995). "Sunk Costs, Firm Size and Firm Growth.", The Journal of Industrial Economics, Volume XLIII, pp.161-172.

[5] Cooley Thomas and Quadrini Vicenzo (1998) "Financial Markets and Firm Dynamics.", American Economic Review, 91, pp. 2186-1310.

[6] Disney, Haskel and Heden (2003). "Entry, Exit and Establishment Survival in UK Manufacturing.", Journal of Industrial Economics, 51, pp. 91-112.

[7] Dunne, Roberts and Samuelson (1989a). "Patterns of Firm Entry and Exit in U.S. Manufacturing Industries.", Rand Journal of Economics, 19, pp. 495-515.

[8] Dunne, Roberts and Samuelson (1989b). "The Growth and Failure of US Manufacturing Plants.", Quaterly Journal of Economics, 96, pp. 671-698.

[9] Dirk Effenberg (2003). "Credit Derivatives: Implications for Credit Markets.", Deutsche Bank Research, International Topics.

[10] Ericson R. and Pakes A. (1995). "Markov Perfect Industry Dynamics: A Framework for Empirical Work.", Review of Economic Studies, pp.5382.

[11] Fazzari, Hubbard and Petersen (1988). "Financing Constraints and Corporate Investment.", Brookings Papers on Economic Activity, 1, pp.141-206.

[12] Gort Michael (1969) "An Economic Disturbance Theory of Mergers.", Quarterly Journal of Economics, 83, pp. 624-642. 
[13] Gort M. and Klepper Steven, (1982) "Time Paths in the Diffusion of Product Innovations.", Economic Journal, 92, pp. 630-653.

[14] Gort, Grabowski and McGunkin (1985) "Organization Capital and the Choice Between Specialization and Diversification.", Managerial Decision Economics, 6, pp. 2-10.

[15] Hayashi Fumio (1982). "Tobin's Marginal q and Average q: A Neoclassical Interpretation.", Econometrica, 50, No. 1, pp. 213-224.

[16] Hayashi Fumio and Inoue Tohru (1991). "The Relation Between Firm Growth and Q with Multiple Capital Goods: Theory and Evidence from Panel Data on Japanese Firms.", Econometrica, 59(3), pp. 731-753.

[17] Hopenhayn Hugo (1992a). "Entry, Exit, and Firm Dynamics in Long Run Equilibrium.", Econometrica, 60(5), pp. 1127-1150.

[18] Hopenhayn Hugo (1992b). "Exit, Selection and The Value of Firms.", Journal of Economic Dynamics and Control, 16, pp. 621-653.

[19] Hopenhayn Hugo (1993). "The Shakeout.", Universitat Pompeu Fabra, Economics Working Paper 33.

[20] Hopenhayn Hugo and Rogerson Richard (1993). "Job Turnover and Policy Evaluation: A General Equilibrium Analysis.", Journal of Political Economy 101, pp. 915-938.

[21] Jensen M. (1993). "The modern Industrial Revolution, Exit, and Control Systems.", Journal of Finance, 48, pp. 831-880.

[22] Jovanovic B. (1982). "Selection and the Evolution of Industry.", Econometrica, 50, pp. 649-670.

[23] Jovanovic B. (1998). "Michael Gort's Contribution to Economics.", Review of Economic Dynamics, 1, pp. 327-337.

[24] Jovanovic B. and Rousseau P. (2001a) "Mergers and Technological Change: 1885-1998.", mimeo, NYU.

[25] Jovanovic B. and Rousseau P. (2001b) "Vintage Organization Capital.", National Bureau of Economic Research, Cambridge, MA. Working Paper No. 8166. 
[26] Jovanovic B. and Rousseau P. (2002a). "The Q-Theory of Mergers.", American Economic Review, 82, No. 2, Papers and Proceedings, pp. 198-204.

[27] Jovanovic B. and Rousseau P. (2002b). "Mergers as Reallocation.", National Bureau of Economic Research, Cambridge, MA. Working Paper No. 9279.

[28] Klepper (1996), "Entry, Exit, Growth, and Innovation over the Product Life Cycle.", The American Economic Review, Volume 86, No. 3, pp. 562-583.

[29] Lambson V. and Jensen F. (1998), "Sunk Costs and Firm Value Variability: Theory and Evidence.", The American Economic Review, Volume 88, No. 1, pp.307.

[30] Lambson V. and Jensen F. (1995), "Sunk Costs and the Variability of Firm Value over time.", The Review of Economics and Statistics, Volume 77, issue 3, August 1995.

[31] Lucas R. (1978). "On the Size Distribution of Business Firms.", Bell Journal of Economics, 9, pp. 508-523.

[32] Lucas R. and Prescott E. (1971). "Investment under uncertainty.", Econometrica, 39, pp.659-81.

[33] Ljungqvist L. and Sargent T. (2000). "Recursive Macroeconomic Theory.", The MIT Press.

[34] Manne Henry (1965). "Mergers and the Market for Corporate Control.", Journal of Political Economy 73, No. 2, pp. 110-120.

[35] Mitchell M. and Mulherin J. (1996). "The Impact of Industry Shocks on Takeover and Restructuring Activity.", Journal of Financial Economics, 41, pp. 193-229.

[36] Pakes A.and Ericson R. (1998). "Empirical Implications of Alternative Models of Firm Dynamics.", Journal of Economic Theory, pp.1-45.

[37] Pautler Paul (2001). "Evidence on Mergers and Acquisitions.", Bureau of Economics, Federal Trade Commission.

[38] Peel M. and Wilson N. (1989). "Some Evidence on Discriminating Between Failing and Distressed Acquired Firms in the UK Corporate Sector.", Managerial and Decision Economics, 10, pp. 209-220. 
[39] Servaes Henry (1991). "Tobin's Q and the Gains from Takeovers.", Journal of Finance, 46, No. 1, pp.409-416.

[40] Schary M.A.(1991). "The Probability of Exit.", Rand Journal of Economics, 22, pp. 339-353.

[41] Simon H. E. and Bonini C. P. (1958) "The Size Distribution of Business Firms.", American Economic Review, 48, 607-617.

[42] Stokey N., Lucas R. and Prescott E. (1989) "Recursive Methods in Economic Dynamics.", Harvard University Press.

[43] Sutton John (1997) "The Gibrat's Legacy.", Journal of Economic Literature, 35 , pp. $40-59$.

[44] Wynne Jose (2005) "The Value of Information in Credit Markets.", mimeo, Duke University, Fuqua School of Business. 